\title{
Practical insights into digital radiology
}

Digital imaging systems for plain radiography

Springer; 2013. p. 79-108. DOI: 10.1007/978-1-4614-5067-2_7

Luís Lança and Augusto Silva

\section{Abstract}

Digital radiography detectors-based on different technological solutions-are currently available for clinical applications and widespread in clinical practice. Computed radiography (CR) and digital radiology systems have been available for clinical applications and the trend over the last few years has become digital. Radiology departments have been changing from traditional screen-film technology to digital technology. This chapter is intended to give the reader a practical understanding about the key aspects concerning digital systems, related to the performance of different technologies, image quality, and dose and patient safety/protection. The discussion around an optimization framework for digital systems is provided.

Keywords: Digital radiography; Detectors; Clinical application; Computed radiography; Digital radiography; Screen-film technology; Performance; Image quality; Dose; Patient safety; Patient protection; Optimization framework; Digital systems. 